Chapter 8

\title{
Small Molecule DMARD Therapy and Its Position in RA Treatment
}

\author{
Hiroaki Matsuno \\ Additional information is available at the end of the chapter \\ http://dx.doi.org/10.5772/53320
}

\section{Introduction}

Small molecule disease-modifying antirheumatic drugs (DMARDs) played a central role in drug therapy for rheumatoid arthritis (RA) before biological preparations (biologics) came into extensive use for the treatment of this disease. Unlike non-steroidal anti-inflammatory drugs (NSAIDs) and steroids, which primarily alleviate the symptoms of RA such as pain and inflammation, DMARDs are known to suppress the progression of RA through their action against immunological abnormalities.

To review the history of the clinical positioning of DMARD therapy, until the beginning of the 1990s, DMARDs were used only in patients showing signs of disease progression (e.g., bone erosion) after NSAIDs or steroid treatment within the framework of pyramid therapy [1]. During the 1990s through the 2000s, the strategy and goals of RA therapy have undergone marked changes following the introduction of methotrexate (MTX) as another treatment option, the expansion of MTX as an anchor drug [2,3,4], endorsement of the usefulness of combined drug therapy involving DMARDs [5], the introduction of biologics into RA treatment [6,7,8], and other advances. In 2002, the American College of Rheumatology (ACR) released its Guidelines on RA Management, clearly indicating DMARDs as first-line drugs for the treatment of RA. As a result, NSAIDs and steroids came to be positioned as auxiliary means of treating RA [9].

The small molecule DMARDs that have been used frequently in Western countries are MTX, sulphasalazine (SASP), hydroxychloroquine (HCQ), leflunomide (LFN), and minocycline (MIN). In Japan, where the repertoire of drugs clinically available differs from that in Western countries, HCQ and MIN are not indicated for RA under the national health policy, and bucillamine (BUC) has been a more popular small molecule DMARD than these 2 drugs. 
The use of biologics such as TNF inhibitors began to spread around the world within several years of their clinical introduction as drugs that exert rapid action and are expected to improve long-term prognosis and to allow patients with RA to maintain physical function [10]. During the 2000s, revisions of the guidelines on RA treatment and criteria for diagnosis of RA were accelerated in various countries, with the goal of treatment shifting from symptom control (anti-inflammatory analgesia) and delayed disease progression to achievement of disease remission and suppression of disease progression. As an accumulation of clinical trial data became available revealing from a long-term perspective the advantageous effects of biologics not found in small molecule DMARDs, including suppression of progression of bone destruction and physical dysfunction [11,12], biologics began to replace small molecule DMARDs, primarily in patients anticipated to have a poor prognosis and those with rapidly advancing disease. In addition, introduction of biologics into therapy at an early stage of active RA has been recommended in some guidelines because of the benefits expected from this kind of drug for maintaining long-term quality of life in many patients [13].

Nonetheless, there are still several open issues involved in the use of biologics, including:

1. presence of a considerable percentage of patients who fail to respond to treatment with biologics[14],

2. heavy economic burdens for individuals and the community due to high drug prices [15],

3. risk of serious adverse reactions (e.g., infection) in some patients [16,17], and so on.

These issues represent obstacles to the establishment of biologics as a predominant means of treatment for RA. In recent years, several reports have been published in the United States and Europe providing data intended to serve as evidence for the view that treatment with a combination of 3 small molecule DMARDs is expected to improve long-term prognosis of RA to an extent comparable with biologics. Following these reports, in Western countries, the guidelines/guidance on RA treatment have been further reviewed, resulting in restatement of the position that small molecule DMARDs are first-line drugs, and a clear statement that combination therapy with small molecule DMARDs should be tried before the therapy with biologics [18]. This chapter will describe the popular small molecule DMARDs currently used for treatment of RA and present a discussion regarding the current position of small molecule DMARDs in RA treatment guidelines/guidance, as well as its background. In addition, 2 new small molecule DMARDs, tofacitinib and iguratimod, are discussed.

\section{Popular small molecule DMARDs}

DMARDs is the collective term for a set of drugs known to suppress the progression of RA via action against immunological abnormalities. These drugs do not exhibit the rapid action on symptoms, i.e., inflammation and pain, exerted by NSAIDs and steroids. 
DMARDs are additionally capable of delaying the progression of bone destruction, but it is rare that remission of RA can be achieved by DMARD mono-therapy in patients with established RA. DMARDs are generally slow in action, taking 1 to 3 months until manifestation of their effects. The response to these drugs varies greatly among individuals, and a number of patients fail to respond to treatment with DMARDs. Furthermore, patients whose disease activity is initially controlled by DMARDs sometimes cease to respond to the drugs (relapse) during prolonged use. Another characteristic of DMARDs is a high incidence of adverse reactions, with the incidence of adverse events with each DMARD being between $20 \%$ and $50 \%$. If adverse reactions are mild, treatment with DAMARDs can be often continued by means of dose reduction or symptomatic treatment, but the risk that patients will develop life-threatening serious adverse reactions, including hematological disorders, renal disorder, and interstitial pneumonia, is common.

Some DMARDs are immune suppressors that are also used for control of host rejection of grafts and treatment of cancer, including MTX, LFN, tacrolimus (TAC), cyclosporine, azathioprine, and cyclophosphamide. The class also includes immune modulating agents, such as SASP, BUC, d-penicillamine, gold compound, and others, as well as HCQ, an anti-malaria agent, and MIN, an antibiotic (Table1).

Here, the popular DMARDs used clinically are described. BUC is approved as a DMARD for treatment of RA only in Japan and Korea, and currently, the use of BUC is almost exclusively confined to Japan, where this drug is still used in quantities as large as SASP, second to MTX among the approved DMARDs.

\section{Methotrexate (MTX)}

MTX is a folic acid antagonist. The drug has been reported to exert immunosuppressive activity through its action (suppression of proliferation) on immune competent cells by means of DNA synthesis inhibition, and to exert anti-inflammatory activity by inducing pooling of adenosine [19]. Details are unknown about the mechanism of its antirheumatic activity, but the drug has shown excellent efficacy and long duration, and it is the most frequently used small molecule DMARD in the world as an anchor drug for RA treatment $[3,4]$. The most recent guidelines recommend early initiation of treatment with MTX as a first-line drug in patients with factors associated with poor prognosis such as positive ACPA, bone erosion, extra-articular symptoms, or restricted physical function [18]. Among the antirheumatic drugs, MTX tends to exert its effects relatively early (within 1 to 2 months) and these effects include suppression of joint destruction [20,21]. 


\begin{tabular}{|c|c|c|c|}
\hline Drug & $\begin{array}{l}\text { Approximate time to } \\
\text { benefit }\end{array}$ & Usual maintenance dose & $\begin{array}{l}\text { Toxicities requiring } \\
\text { monitoring }\end{array}$ \\
\hline Hydroxychloroquine & 2-6 months & $200 \mathrm{mg}$ twice a day & Macular damage \\
\hline Sulfasalazine & 1-3 months & $1,000 \mathrm{mg} \mathrm{2-3}$ times a day & Myelosuppression \\
\hline Methotrexate & 1-2 months & $\begin{array}{l}\text { Oral 7.5-20 mg/week; } \\
\text { injectable } 7.5-20 \mathrm{mg} / \text { week }\end{array}$ & $\begin{array}{l}\text { Myelosuppression, hepatic } \\
\text { fibrosis, cirrhosis, pulmonary } \\
\text { infiltrates or fibrosis }\end{array}$ \\
\hline Leflunomide & $\begin{array}{l}\text { 4-12 weeks (skewed } \\
\text { earlier) }\end{array}$ & $\begin{array}{l}20 \mathrm{mg} / \text { day in a single } \\
\text { dose, if tolerated; } \\
\text { otherwise, } 10 \mathrm{mg} / \text { day }\end{array}$ & $\begin{array}{l}\text { Diarrhea, alopecia, rash, } \\
\text { headache, theoretical risk of } \\
\text { immunosuppression infection }\end{array}$ \\
\hline Bucillamine & 1-3 months & $100-200 \mathrm{mg}$ a day & $\begin{array}{l}\text { Myelosuppression, } \\
\text { hepatotoxicity, proteinuria }\end{array}$ \\
\hline Tacrolimus & $6-12$ weeks & $3 \mathrm{mg}$ a day & $\begin{array}{l}\text { Renal insufficiency, anemia, } \\
\text { hypertension, Impaired } \\
\text { glucose tolerance }\end{array}$ \\
\hline Azathioprine & 2-3 months & $50-150 \mathrm{mg} /$ day & $\begin{array}{l}\text { Myelosuppression, } \\
\text { hepatotoxicity, } \\
\text { lymphoproliferative disorders }\end{array}$ \\
\hline D-penicillamine & 3-6 months & $250-750 \mathrm{mg} / \mathrm{day}$ & Myelosuppression, proteinuria \\
\hline Gold, oral & 4-6 months & $3 \mathrm{mg}$ twice a day & Myelosuppression, proteinuria \\
\hline Gold, intramuscular & 3-6 months & $\begin{array}{l}25-50 \mathrm{mg} \text { intramuscularly } \\
\text { every } 2-4 \text { weeks }\end{array}$ & Myelosuppression, proteinuria \\
\hline Minocycline & 1-3 months & $100 \mathrm{mg}$ twice a day & $\begin{array}{l}\text { Hyperpigmentation, dizziness, } \\
\text { vaginal yeast infections }\end{array}$ \\
\hline Cyclosporine & $6-12$ weeks & $2.5-4 \mathrm{mg} / \mathrm{kg} / \mathrm{day}$ & $\begin{array}{l}\text { Renal insufficiency, anemia, } \\
\text { hypertension, Impaired } \\
\text { glucose tolerance }\end{array}$ \\
\hline
\end{tabular}

Table 1 summary of small molecule DMARDs

Adverse reactions to MTX include infection, stomatitis, glossitis, nausea, hepatic dysfunction [22], and others. It is known that these adverse reactions are more likely to appear in patients with compromised renal function and in elderly patients, and that they can be reduced by concomitant use of folic acid or leucovorin [23,24,25]. Interstitial pneumonia and bone marrow suppression are known as serious adverse reactions. Interstitial pneumonia can develop suddenly and is sometimes intractable [26]. Marrow suppression involves impaired hematopoiesis. Both of these reactions are serious and require hospitalization. As a rule, MTX is administered once weekly via an oral or parenteral route at an initial dose level of 7.5 to $15 \mathrm{mg}$, with the dose being gradually increased up to $25 \mathrm{mg} /$ week if responses are insufficient. In Japan, MTX is only administered orally, at an initial dose level of $6 \mathrm{mg} /$ week. The dose is gradually increased up to $16 \mathrm{mg}$ if responses are insufficient. The weekly dose level may be divided into 1 to 3 doses in 1 or 2 days. It is known that the effects of MTX are strengthened by concomitant use of biologics [27].

\section{Sulphasalazine (SASP)}

This drug exerts action relatively rapidly (in 1 to 2 months) among the DMARDs. Like MTX, SASP has been reported to exert anti-inflammatory activity by inducing pooling of adeno- 
sine [28], and to have immunomodulating effects as well, e.g., suppression of antibody production [29]. The antirheumatic activity of SASP has not been sufficiently clarified, but because it suppresses joint destruction [20], it is considered as an option for treatment of RA with MTX. As compared to other DMARDs, SASP can be characterized by low nephrotoxicity, and the risk for teratogenicity in pregnant women is also considered to be lower with SASP than with other DMARDs. Adverse reactions to SASP include liver disorder, drug eruption, bone marrow disorders, and others. Because the incidence of gastrointestinal disorders as an adverse reaction is high with the bulk form of SASP, it is usually administered in the form of an enteric-coated tablet for the treatment of RA. In Western countries, this drug is usually recommended for treatment at a dose level of 2 to $3 \mathrm{mg} /$ day, while in Japan, the upper limit of the dose level is set at $1 \mathrm{mg} /$ day.

\section{Leflunomide (LFN)}

LFN is a metabolic antagonist capable of suppressing the proliferation of T lymphocytes through pyrimidine synthesis inhibition [20]. This drug has been reported to suppress joint destruction. It is characterized by the long half-life of its active form. Adverse reactions to LFN include infection, diarrhea, bone marrow disorders, hypertension, liver disorder, nausea, alopecia, and others. Interstitial pneumonia is an adverse reaction that requires utmost caution and is potentially fatal. LFN has been reported to be teratogenic [30,31]. For a couple planning pregnancy, it is necessary for both partners to take cholestyramine to eliminate the active metabolites of LFN completely. Because of the long the half-life of the active metabolite in vivo, the drug is administered at a loading dose level $(100 \mathrm{mg})$ for the first 3 days, followed by administration at a constant dose level $(20 \mathrm{mg} /$ day $)$.

\section{Hydroxychloroquine (HCQ)}

HCQ was used as an anti-malaria agent before it was used as an antirheumatic drug [32]. The anti-malaria activity of HCQ is considered to have no relationship to its antirheumatic activity. HCQ is believed to suppress antigen presentation by elevating the $\mathrm{pH}$ of the cytoplasmic compartment of antigen-presenting macrophages [33]. More recently, it was reported that HCQ acts on the toll-like receptor to manifest effects on the immune system [34]. The efficacy of HCQ is less than that of MTX, but HCQ has an excellent safety profile. For this reason, HCQ is used for the treatment of mild RA [35]. Uncombined HCQ treatment does not suppress the progression of bone destruction. Although the tolerability is high, adverse reactions such as nausea and dizziness occasionally appear. Furthermore, the drug has a high affinity for the retina and thus exerts high ocular toxicity. This is the reason that use of the drug is not approved in some countries. Although retinal disorders induced by HCQ are irreversible and if severe can lead to blindness, recovery from retinal disorders is sometimes possible if they are detected early. HCQ is also used occasionally for treatment of articular 
and skin symptoms of SLE. For the treatment of RA, the drug is administered at a dose of $400 \mathrm{mg} /$ day.

\section{Minocycline (MIN)}

The US Food and Drug Administration (FDA) has not approved MIN for treatment of RA. However, a slow efficacy of this drug against RA has been shown in some double-blind trials $[36,37,38,39]$. Although the usefulness of this drug as a means of treatment for RA is low, it has evidenced effects at early stages of RA. Compounds of the tetracycline family are known to suppress matrix metalloproteinase [40], and this action is believed to suppress narrowing of the joint space in patients with RA. The activity of MIN as an antibiotic is considered to have no relationship to its antirheumatic activity.

\section{Bucillamine (BUC)}

BUC has been approved as a means of RA treatment in only Japan and Korea. As noted, at present, its use is almost exclusively confined to Japan. BUC is used as frequently as SASP in Japan, and this frequency of use is second to MTX. Its antirheumatic activity is slightly stronger, that is comparable to or higher than, that of SASP [41,42]. For this reason, BUC is used for treatment of mild to moderate RA. The pharmacologic actions that have been reported as likely to be involved in the drug's antirheumatic effects include suppression of cytokine production in the synoviocytes [43], suppression of antibody production from Blymphocytes [44,45], and suppression of osteoclast differentiation [46]. According to a recent report, the effect of this drug in inhibiting Akt signals is involved in the suppression of antibody production from B-lymphocytes and the suppression of cytokine production by the synoviocytes $[47,48]$. Numerous adverse reactions including renal disorders and skin disorders are known, with serious adverse reactions including interstitial pneumonia and hematological disorders, and therefore patients must be watched closely. When used for the treatment of RA, BUC is administered at an initial dose of $100 \mathrm{mg} / \mathrm{day}$, with a gradual increase up to $300 \mathrm{mg} /$ day if efficacies are insufficient.

\section{Tacrolimus (TAC)}

TAC was initially sold as a drug for suppression host rejection of grafts. In 2005, its indication was expanded to encompass treatment of RA. The known effects of TAC include inhibition of the proliferation and differentiation of T lymphocytes involved in persistence of RAassociated inflammation and suppression of inflammatory cytokine production. The effect of this drug on RA is not strong when used as mono-therapy. It shows excellent efficacy when used as an additional drug in combination therapy for patients who have insufficient 
response to MTX alone [49]. In Western countries, this drug is not used frequently because the results of clinical trials of mono-therapy have been unsatisfactory, and the ACR has not advocated the use of TAC as a means of treating RA because of its insufficient efficacy [18]. Adverse reactions to TAC include headache, renal disorders, hyperglycemia, hyperuricemia, hypertension, and others. Since TAC is less likely to affect the respiratory system, it is occasionally used in patients who have respiratory complications. When used for the treatment of RA, this drug is usually administered at a dose of $3 \mathrm{mg} /$ day, and at $1.5 \mathrm{mg} /$ day in elderly patients.

\section{Gold Compound}

Two formulations of gold compound (injection and oral-dose preparations) are available. The efficacy and safety profiles partially differ between these 2 forms. Injection is performed intramuscularly once weekly at an initial dose of $50 \mathrm{mg} /$ week, followed by maintenance dosing (once every 2 to 4 weeks). The response rate is relatively high, but effects are usually not evident until after 3 to 6 months. The frequency of discontinuation of treatment due to adverse reactions is high, with skin and mucosal disorders being the most frequent causes for discontinuation. Adequate monitoring for proteinuria and renal dysfunction is necessary, and care is also needed regarding hematological disorders, since leukopenia, thrombocytopenia, and hypoplastic anemia can develop following treatment with this drug. The oraldose preparation is administered twice daily at a dose of $3 \mathrm{mg} /$ dose. The efficacy of the oraldose preparation is less than that of the injection and takes up to 9 months to appear. Adverse reactions to the oral-dose preparation are akin to those of the injection, although the incidence of renal and hematological disorders is slightly lower with the oral preparation.

\section{Azathioprine}

This drug is a purine analog and is shown to exert immunosuppressive effects by antimitotic action induced by inhibiting the synthesis of DNA and proteins. The efficacy of this drug against RA is comparable to that of other slow-acting drugs. Adverse reactions to azathioprine include gastrointestinal disorders, liver disease, leukopenia, and others.

\section{Cyclosporine}

Cyclosporine is an immune suppressor that is generally used as means of suppressing host rejection of grafts. This drug suppresses the production and physiological actions of interleukin-2 and lymphocyte growth factor, taking 6 to 12 weeks before manifestation of its efficacy against RA. Frequently observed adverse reactions to this drug include renal disorders, hyper- 
tension, gingival thickening, increased body hair, and others. Cyclosporine is recommended only for treatment of severe and advanced RA that has failed to respond to other drugs.

\section{Cyclophosphamide}

Cyclophosphamide is an alkylating agent with nonspecific cytotoxic activity. It suppresses the immune system by disturbing lymphocytes in a nonspecific manner. This dug has been positioned to play an important role in the treatment of SLE and vasculitis. It is rarely used for patients with RA because of strong adverse effects.

\section{Changes in the position of small molecule DMARDs in the treatment of RA}

According to the pyramid therapy [1] model that had been established by the beginning of the 1990s, RA treatment focused on alleviation of symptoms (pain, inflammation, etc.) with the use of NSAIDs and steroids at sufficiently high doses. Use of antirheumatic drugs was confined to cases with marked progression of bone erosion and other severe manifestations. It was noted that in cases requiring treatment by NSAIDs and steroids inflammation appeared to subside gradually by means of burnout over time. However, the RA itself remained unchanged and bone destruction continued to advance, accompanied by progression of joint dysfunction [50]. The primary drug therapy in those days played only the role of suppressing symptoms (i.e., pain and swelling), and it could not prevent progression of bone destruction, joint dysfunction, and other morbidity.

This situation changed dramatically during the period from the latter half of the 1990s to the 2000s. MTX had become clinically available for use in the treatment of RA in the 1980s to 1990s, and subsequently began to be used extensively as an anchor drug for the treatment of RA $[2,3,4]$. The term anchor drug refers to any drug used as a "protagonist" in the treatment of RA. In the management of RA, MTX was positioned as a drug whose necessity would be determined on the basis of the severity of the disease, and which would become indispensable in cases where the disease severity exceeded a certain level. After the mid-1990s, a series of data were published that provided new evidence of the efficacy of combined DMARD therapy (2 or 3 DMARDs) as compared to DMARD mono-therapy, stimulating active adoption of DMARD combination therapy. During this time, MTX also came to be positioned as a key drug in combination therapy, and to date, the prominence MTX as an anchor drug has not changed [5]. From the late 1990s to the 2000s, biologics, primarily TNF inhibitors, began to be introduced clinically as drugs expected to improve long-term prognosis and to maintain physical function $[6,7,8]$, and by the 2000s, these events had led to an acceleration in some countries to revise existing treatment guidelines and diagnostic criteria for RA, which was accompanied by a shift of the focus of treatment from anti-inflammatory analgesia and delay of disease progression to achievement of disease remission and prevention of progres- 
sion. The RA management guidelines that were published by the ACR in 2002 positioned DMARDs as first-line drugs for RA treatment, which were to be started within 3 months after disease onset, while positioning NSAIDs and steroids as auxiliary drugs for symptoms such as pain and inflammation [9]. These guidelines additionally recommended switching patients to different DMARDs if the initially prescribed DMARDs failed to exert sufficient efficacy within 3 months of the initiation of treatment. This guideline clearly positioned MTX as an anchor drug, allowing clinicians to acknowledge that a current framework of RA treatment had been decided at that time. It was also recommended by this guideline that biologics should be used in cases that were failing to respond well to treatment with DMARDs, including MTX. We may infer that in their early days, the clinical use of biologics was confined to intractable cases because this class of drug had not yet been evaluated in a sufficient number of cases (Figure 1).

During the period from the late 1990s to 2000s, as a series of new biologics were introduced and the clinical trial data on these drugs accumulated, it was suggested by some of these data that active use of biologics beginning soon after disease onset might be advantageous in some patients in terms of efficacy of long-term RA management, notably when focusing on the effects of biologics in suppressing progression of bone destruction and physical dysfunction, which were not seen with small molecule DMARDs [11,12]. In some patients, primarily those anticipated to have poor prognoses and those with rapidly progressive RA, biologics began to replace small molecule DMARDs. In 2008, noting this trend, the ACR made public a new recommendation on RA treatment that stated that the use of TNF inhibitors should be recommended as an option for first-line

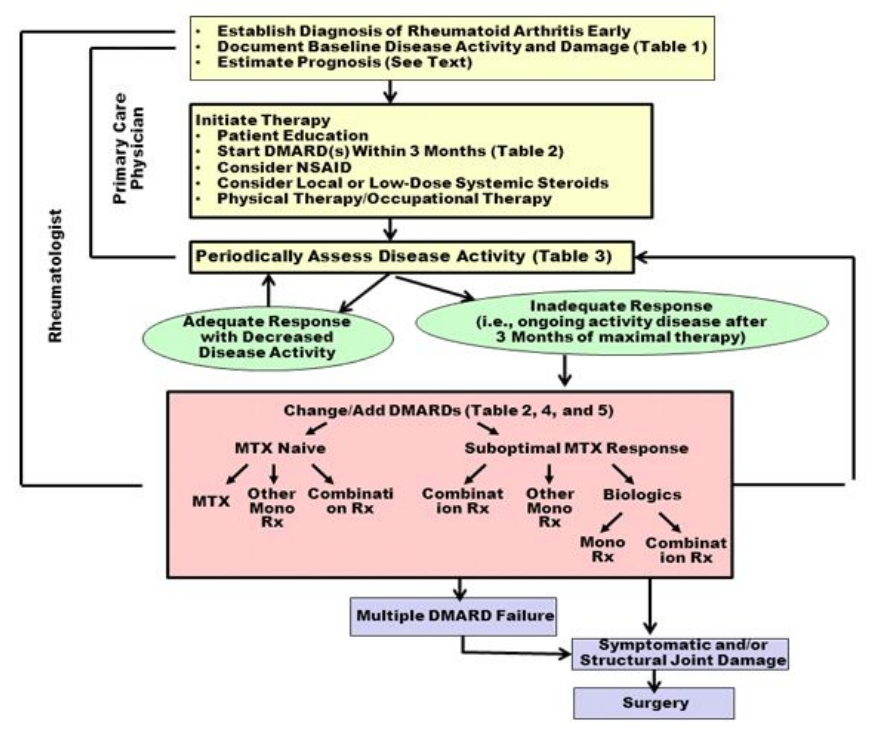

Figure 1. Guidelines for the management of rheumatoid arthritis: 2002 Update 
medication for patients with high disease activity at 3 months to less than 6 months after disease onset, and patients with high disease activity and factors associated with poor prognosis at less than 3 months after disease onset [18] (Figure 2). Campaigns promoting a better long-term prognosis by earlier start of treatment with biologics based on these developments and bolstered by financial programs that assisted patients with out-of-pocket payments for biologics created stiff competition over biologics among manufacturers, and has reportedly promoted an increase in the quantity of biologics used for RA treatment. However, there are still many open issues surrounding biologics, including the high percentage of patients who fail to respond to biologics [14], the high price that causes large burdens on individuals and society [15], and the risk of serious adverse reactions such as infection $[16,17]$. The use of DMARDs, primarily in combination therapy, has also fallen under renewed scrutiny following publication of new studies. These events may stimulate further revision of the current guidelines/guidance on RA treatment.

Restriction of the use of biological preparations due to the necessity of out-of-pocket payment of their cost

Figure 3 illustrates the sales of 3 biological TNF antagonists per 100,000 populations in each country. It shows that biologics are used a lot in European countries such as Norway and Sweden. In these countries, patients are usually required to pay no money or only very small amounts (less than 1,000 yen) as out-of-pocket payment during each visit to a medical facility $[10,51]$. The consumption tax rate is high (about 20 to 30\%) in these countries, and a large portion of the consumption tax collected is spent for social welfare, including medical expense. This is the reason why the out-of-pocket payment is small for patients in these countries.

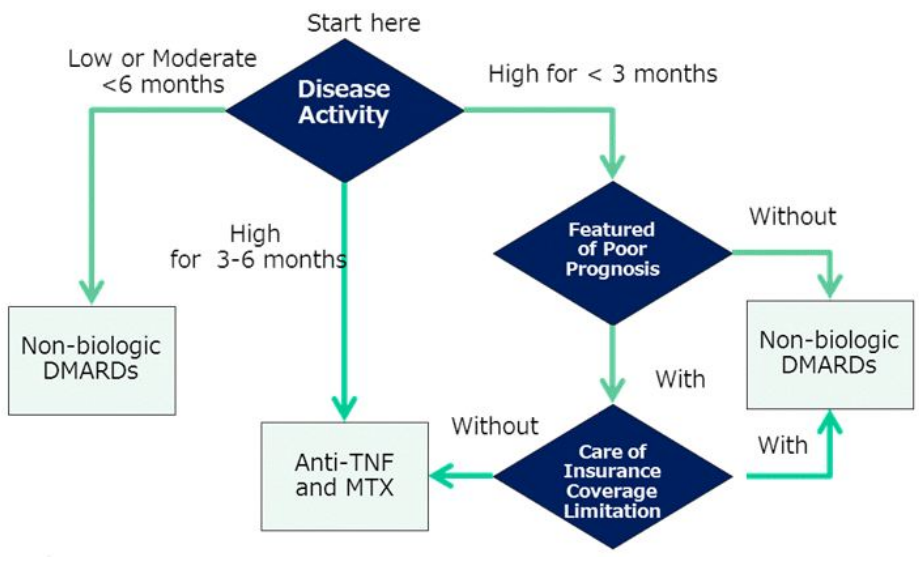

Figure 2. American College of Rheumatology 2008 recommendations on indications for the use of biologic Diseasemodifying antirheumatic drugs in patients with $\mathrm{RS}<6$ months

The United States, on the other hand, is the only developed country having no universal public health insurance. Excluding Medicare and Medicaid for elderly people, physically 
handicapped citizens and low-income families, healthcare in the United States depends on private sector insurance not mandatory for individual citizens. The premium for private health insurance is high, and a high percentage of uninsured people is often highlighted as a social problem in this country. For individuals covered by health insurance, the out-of pocket payment is not very large, although it varies depending on the insurance plan selected by individuals. Furthermore, unique campaigns by pharmaceutical companies are available in the United States, promoting the treatment with biologics. Under such campaigns, a majority of individual patient drug cost will be borne by the manufacturer to take over if the patients agree to treatment with specific drugs for a certain period of time and are registered with the treatment programs (RemiStart, Enbrel Support, My Humira, etc).

In Japan, however, annual out-of-pocket payment amounting to about 400,000 to 500,000 yen (about 5000 to 6500 dollars) is needed for many patients receiving treatment with biologics, excluding some patients covered by social welfare programs for reduction of out-ofpocket payment of healthcare expenses (specific physically handicapped individuals, individuals covered by poverty program, and so on). (Japan and Korea are the only countries belonging to the OECD where individuals covered by health insurance are required to make out-of-pocket payment to bear $30 \%$ of health care costs.) This amount of out-of-pocket payment is about 25 times as large as the out-of-pocket payment needed for conventional DMARDs. There are patients who give up receiving treatment with biologics because they cannot afford to pay the expense [51].

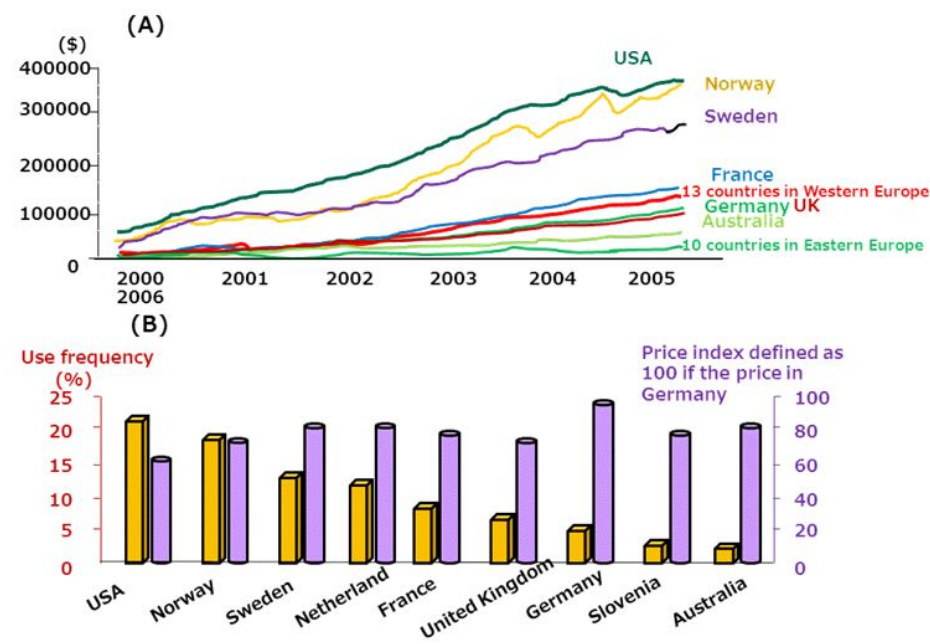

Figure 3. Sales of three biologics TNF antagonists per 100,000 population (A) and Price index and the percentage of patients using biologics TNF antagonist in the world in 2006 (B) 


\section{Current standard of care for RA}

It has been shown that intervention with biologics at early stages of RA is expected to control the disease activity and suppress subsequent joint destruction, thus facilitating remission of RA, biologics free and cure [52]. However, according to the Best study [53], the longterm outcome of treatment differs little among different treatment strategies. It has thus been suggested to be more important to practice tight control through adjusting treatment flexibly depending on the disease activity in individual cases, instead of selecting biologics from the beginning (Figure 4).

In 2012, the ACR published the "2012 Update of the 2008 American College of Rheumatology Recommendations for the Use of Disease-Modifying Antirheumatic Drugs and Biologic Agents in the Treatment of Rheumatoid Arthritis," and recommended separate methods of treatment for patients at early stages of RA (less than 6 months after onset) and patients with established RA (6 months or more after onset) [18]. According to the revised guidelines, intervention with biologics is recommended for cases of established RA if the RA cannot be adequately controlled with recommended DMARD therapies (Figure 5). The guidelines also state that use of TNF inhibitors deserves to be considered even in patients with early stage RA if factors associated with poor prognosis are present and the disease activity is high, although it seems to be accepted that biologics have become a mode of treatment that is considered, as a rule, only in cases where the activity of RA cannot be controlled sufficiently by adequate treatment with small molecule DMARDs, including MTX.

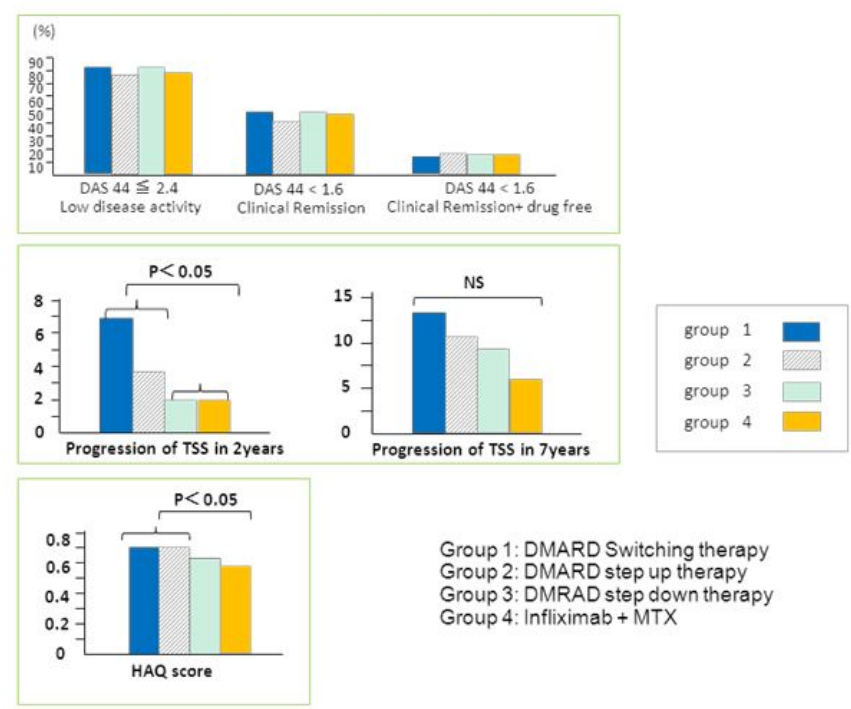

Figure 4. Seven year Results of DAS steered treatment in the BeSt Study: clinical and radiological outcome 
Under the National Health Service (NHS) in the United Kingdom, in which prescription payments for individual patients are borne by the government, RA treatment is guided by the recommendations of the National Institute for Health and Clinical Excellence (NICE) [54]. The procedure for treatment under this system is more concrete than the ACR recommendations, and permits moving to therapy with biologics (anti-TNF preparations) or tocilizumab in cases that are poorly controlled despite attempts of treatment with DMARD combination therapy including MTX, even at the highest possible dose levels (Figure 6). However, permission for the use of these biologics under the British system requires that the manufactures bear any individual drug costs exceeding £9296 per year.

\section{Comparison between small molecule DMARDs combination therapy and biologics plus MTX combination therapy}

Regarding drug therapy at early stages of RA, the two-year data were recently reported on multicenter comparative clinical studies of three small molecule DMARDs combination therapy (MTX + SASP + HCQ) and biologics plus MTX combination therapy in the United States (TEAR study) [55] and Sweden (Swefot trial) [56]. In the TEAR study, the outcome as to DAS28-ESR did not differ between the oral triple therapy and the etanercept plus MTX combination therapy (first endpoint), and ACR20 and 50 was observed no difference between the two groups. The only significant difference was between two groups for ACR70 (Figure 7). In the

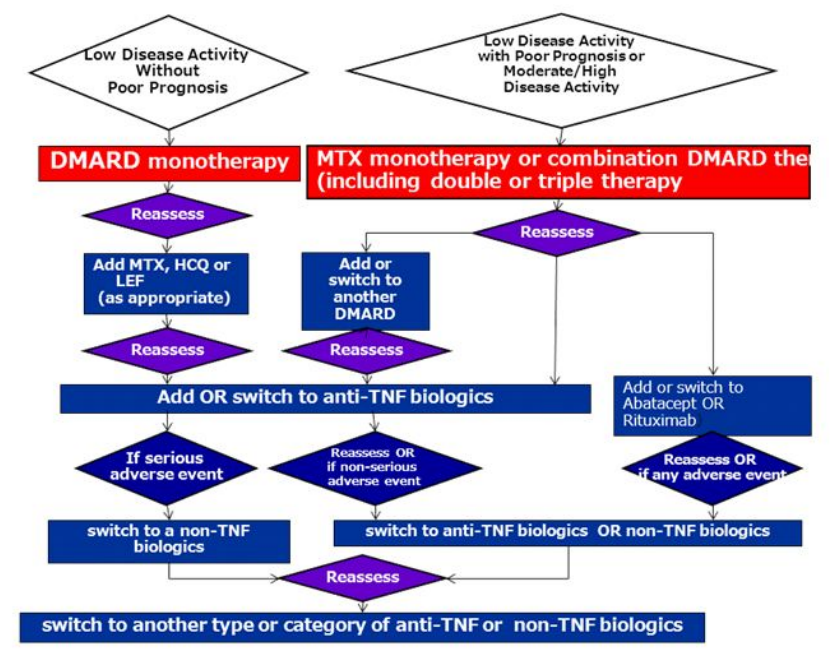

Figure 5. update of the 2008 American College of Rheumatology recommendations for the use of disease-modifying antirheumatic drugs and biologic agents in the treatment of rheumatoid arthritis. 


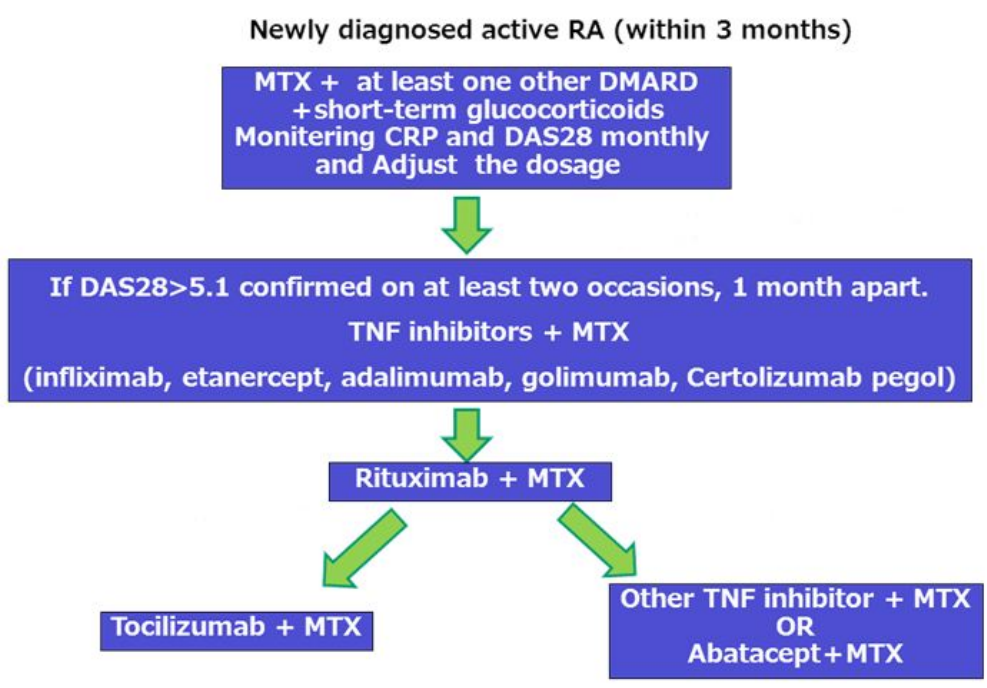

Figure 6. Summary of the management of rheumatoid arthritis in National Institute for Healt and Clinical Exellence guideline for rheumatoid arthritis

Swefot trial, there was no difference between the three small molecule DMARDs combination therapy group and the infliximab plus MTX combination therapy group in terms of ACR 20, 50 or 70 or EULAR good/moderate response. The TEAR study revealed no difference between the oral triple therapy group and the biologics plus MTX combination therapy group from the $12^{\text {th }}$ month on after the start of treatment, while the Swefot trial disclosed higher efficacy of biologics plus MTX combination therapy during the first 6-12 months of treatment, followed by gradual disappearance of the inter-group difference during the twoyear follow-up period. Also according to the long-term data from Best study conducted in the Netherlands [53], there was no significant difference in clinical improvement or the degree of bone/joint destruction on radiographic examination between Group 3 (treatment started with 3 drugs, MTX + SASP + steroid) and Group 4 (treatment started with biological preparations).

Regarding the degree of bone/joint destruction on radiographic examination, both TEAR study and Swefot trial demonstrated significant reduction in the biologics plus MTX combination therapy group, with the inter-group difference being 1-2 in terms of total Sharp Heijde score (full point: 448) of the mean progression of destruction per year relative to the baseline at the start of treatment. It might be thought that it is questionable to use the expensive biologics as the initial means of intervention into RA if only such slight suppression of bone/joint destruction on X-ray can be achieved. 

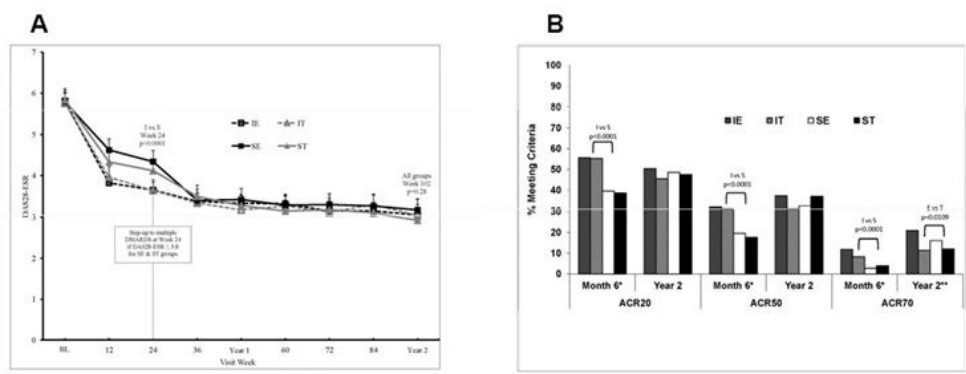

Figure 7. Results from the TEAR trial: oral triple Therapy vs. etanercept plus methotrexate in early RA (A): Observed DAS28-ESR,(B): Percentage of participants in TEAR achieving ACR20, 50, and 70 criteria at time of step-up at 6 months and at the 2 year conclusion of the study.

\section{Three small molecule DMARD combination therapy in Japan (JaSTAR study)}

The ACR recommendation and the NICE (U.K.) guidance state that the three DMARDs combination therapy should be applied before treatment with biologics [18,54]. In Japan, HCQ has not been approved for use in the treatment of RA because of adverse reactions. The three drug combined therapy (MRX + SASP + HCQ) is therefore not practically possible in Japan. We thus started a multicenter comparative clinical study on treatment of early stage RA with three small molecule DMARD combination therapy and biological TNF antagonists plus MTX combination therapy, involving nationwide 32 facilities of rheumatologist in Japan (JaSTAR study: Japan Strategic Treatment of Aggressive RA) [57].

The DMARDs used in the JaSTAR study were MTX, SASP and Bucillamine (Buc). Buc was used instead of HCQ for the following reasons:

1. Buc is a DMARD used frequently in Japan; and

2. this combination of three drugs with Recommendation Level " $\mathrm{A}$ " according to the Guidelines of the Ministry of Health, Labour and Welfare seemed to be appropriate for this study [41].

To date, case registration has been completed, achieving the targeting number (160 cases), and each patient enrolled to the study is now under follow-up. Interim analysis of the data during the first 6 months revealed a similar DAS28 remission rate between the three DMARDs combination therapy group and the biological TNF antagonists plus MTX combination therapy group (Figure 8). The treatment continuation rate among the 33 cases where one-year data have been analyzed was superior over the anti-TNF therapy continuation rate previously reported from the DANBIO registry [68] (Figure 9). We are looking forward to the results from final data analysis. 


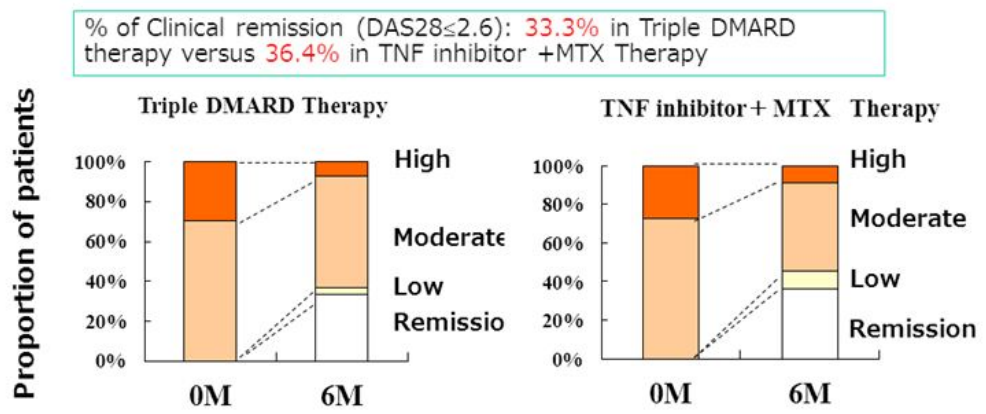

High: DAS28 > 5.1, Moderate: $3.2 \leq$ DAS28 $\leq 5.1$, Low: DAS28<3.2 Remission: DAS28 $\leq 2.6$

Figure 8. Distribution of disease activity of patients before and after treatment for 6 monts in JaSTAR Study

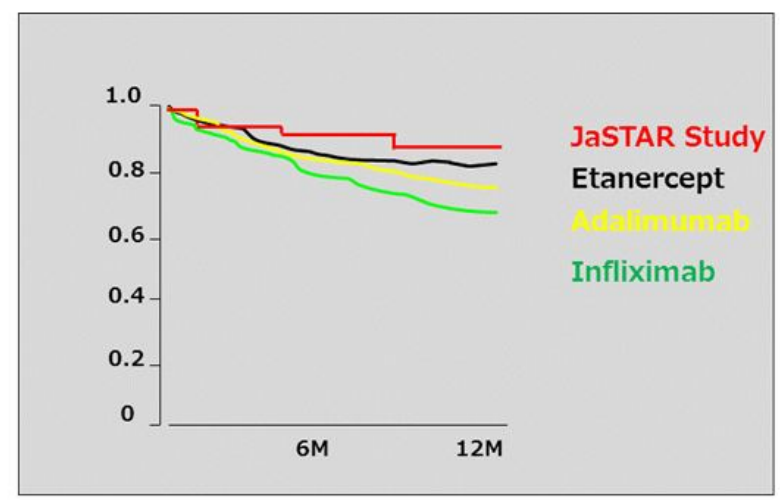

Figure 9. Cumulative continuation rate of triple DMARDs combination therapy in JaSTAR Stady, Cumulative continuation rate of TNF inhibitors in DANBIO study was superimposed.

\section{Introduction of new small molecule DMARDs for RA treatment}

It is known that among the drugs currently used for treatment of RA, those targeted at cytokines, all of which fall under the category of biologics, have yielded particularly favorable outcomes. However, unless the open issues mentioned above are resolved, it is unlikely that biologics will play a central role in the treatment of RA. In 2012 and 2013, there were 2 new DMARDs scheduled for introduction for RA treatment. One of them, tofacitinib, has been developed with attention focused on the role of cytokines in RA. If tofacitinib is shown in 
clinical practice to be a means of RA treatment possessing both the advantages of biologics and the advantages of small molecule DMARDs, it is expected that another paradigm shift will occur in RA management. The 2 new DMARDs are described in further detail below.

\section{Tofacitinib}

Tofacitinib has been developed as a drug for treatment of RA. It is shown to be an inhibitor of Janus kinase 3 (JAK3), an enzyme reported to be involved in cytokine receptor signal transduction. To date, tofacitinib has been experimentally shown to suppress all JAKs (1 through 3), rather than manifesting selective action against any particular JAK. Tofacitinib suppresses cytokines through inhibition of JAK-stat signals. In May 2012, the US FDA issued an approval recommendation for the use of this drug in adults with moderate or severe RA. According to the results of clinical trials, treatment with tofacitinib for 3 months achieved a semi-favorable (about 50\%) ACR20 in patients who were responding poorly to TNF inhibitor treatment, with a placebo group achieving about $25 \%$. Clinical trials have also been conducted for tofacitinib as a first-line drug, and in patients responding poorly to MTX, each yielding favorable outcomes. This drug is therefore reported to be promising not only as an additional option during biologic therapy but also as a first-line drug. Adverse reactions that require caution are elevations in blood cholesterol levels and neutrophilia.

\section{Iguratimod}

Iguratimod was formulated as a COX2 inhibitor and was later found to have immune modulating activity. It was thus developed as a DMARD. Iguratimod has been shown to be useful in combination with other drugs in patients failing to respond well to MTX. Elevation in liver enzymes is known as an adverse reaction.

\section{Conclusion}

As detailed herein, small molecule DMARDs have played a central role in treatment of RA since before the introduction of biologics, and it has been shown that modification of DMARD regimens (e.g., consideration of combination therapy beginning soon after disease onset) can improve the long-term prognosis, allowing small molecule DMARDs to serve as valid alternatives for biologics in RA treatment. While it is also known that treatment with biologics is useful in cases of high activity RA, even in these cases, there may be patients for whom combination therapy using existing DMARDs should be considered before introduction of biologics. Further changes in the paradigm of RA treatment are expected pending results of clinical use of new oral-dose small molecule DMARDs that have shown effects similar to both biologics and small molecule DMARDs. 


\title{
Author details
}

\author{
Hiroaki Matsuno*
}

Address all correspondence to: info@toyama-ra.com

Matsuno Clinic for Rheumatic Diseases, USA

\section{References}

[1] Schenkier, S., \& Golbus, J. (1992). Treatment of rheumatoid arthritis. New thoughts on the classic pyramid approach. Postgrad Med 289-92, 91(1), 285-6.

[2] Michael, E., Weinblatt, M. D., Jonathan, S., Coblyn, M. D., David, A., Fox, M. D., Patricia, A., Fraser, M. D., Donald, E., Holdsworth, M. D., David, N., Glass, M. B., Ch, B., David, E., \& Trentham, M. D. (1985). Efficacy of Low-Dose Methotrexate in Rheumatoid Arthritis. N Engl J Med, 312, 818-822.

[3] Sokka, T., \& Pincus, T. (2002). Contemporary disease modifying antirheumatic drugs (DMARD) in patients with recent onset rheumatoid arthritis in a US private practice: methotrexate as the anchor drug in $90 \%$ and new DMARD in 30\% of patients. Rheumatol, 29(12), 2521-4.

[4] Pincus, T., Yazici, Y., Sokka, T., Aletaha, D., \& Smolen, J. S. Methotrexate as the "anchor drug" for the treatment of early rheumatoid arthritis. Clin Exp Rheumatol, 21(5, 31), S179-85.

[5] O’Dell, J. R., Haire, C. E., Erikson, N., Drymalski, W., Palmer, W., Eckhoff, P. J., Garwood, V., Maloley, P., Klassen, L. W., Wees, S., Klein, H., \& Moore, G. F. (1996). Treatment of rheumatoid arthritis with methotrexate alone, sulfasalazine and hydroxychloroquine, or a combination of all three medications. N Engl J Med, 334, 1287-91.

[6] Lipsky, P. E., van der Heijde, D. M., St, Clair. E. W., Furst, D. E., Breedveld, F. C., Kalden, J. R., Smolen, J. S., Weisman, M., Emery, P., Feldmann, M., Harriman, G. R., \& Maini, RN. (2000). Anti-Tumor Necrosis Factor Trial in Rheumatoid Arthritis with Concomitant Therapy Study Group. Infliximab and methotrexate in the treatment of rheumatoid arthritis. Anti-Tumor Necrosis Factor Trial in Rheumatoid Arthritis with Concomitant Therapy Study Group. N Engl J Med, 343, 1594-602.

[7] Maini, R., St Clair, E. W., Breedveld, F., Furst, D., Kalden, J., Weisman, M., Smolen, J., Emery, P., Harriman, G., Feldmann, M., \& Lipsky, P. (1999). Infliximab (chimeric anti-tumour necrosis factor alpha monoclonal antibody) versus placebo in rheumatoid arthritis patients receiving concomitant methotrexate: a randomised phase III trial. ATTRACT Study Group. Lancet, 354, 1932-9. 
[8] Weinblatt, ME, Kremer, J. M., Bankhurst, A. D., Bulpitt, K. J., Fleischmann, R. M., Fox, R. I., Jackson, C. G., Lange, M., \& Burge, D. J. (1999). A trial of etanercept, a recombinant tumor necrosis factor receptor:Fc fusion protein, in patients with rheumatoid arthritis receiving methotrexate. $N$ Engl J Med, 340, 253-9.

[9] Guidelines for the management of rheumatoid arthritis:. American College of Rheumatology Subcommittee on Rheumatoid Arthritis Guidelines. Update., Arthritis Rheum., 46(2), 328-46.

[10] Jönsson, B., Kobelt, G., \& Smolen, J. (2008). The burden of rheumatoid arthritis and access to treatment: uptake of new therapies. Eur J Health Econ, 8(2), S61-86.

[11] van der Heijde, D., Klareskog, L., Rodriguez-Valverde, V., Codreanu, C., Bolosiu, H., Melo-Gomes, J., Tornero-Molina, J., Wajdula, J., Pedersen, R., Fatenejad, S., \& TEMPO Study Investigators. Comparison of etanercept and methotrexate, alone and combined, in the treatment of rheumatoid arthritis: two-year clinical and radiographic results from the TEMPO study, a double-blind, randomized trial. 54, 1063-74.

[12] van der Heijde, D., Breedveld, F. C., Kavanaugh, A., Keystone, E. C., Landewé, R., Patra, K., \& Pangan, A. L. (2010). Disease activity, physical function, and radiographic progression after longterm therapy with adalimumab plus methotrexate: 5-year results of PREMIER. J Rheumatol, 37, 2237-46.

[13] Saag, K. G., Teng, G. G., Patkar, N. M., Anuntiyo, J., Finney, C., Curtis, J. R., Paulus, H. E., Mudano, A., Pisu, M., Elkins-Melton, M., Outman, R., Allison, J. J., Suarez, Almazor. M., Bridges, S. L. Jr, Chatham, W. W., Hochberg, M., Mac Lean, C., Mikuls, T., Moreland, L. W., O'Dell, J., Turkiewicz, A. M., \& Furst, D. E. (2008). American College of Rheumatology. American College of Rheumatology '08 recommendations for the use of nonbiologic and biologic disease-modifying antirheumatic drugs in rheumatoid arthritis. Arthritis Rheum, 59, 762-84.

[14] Finckh, A., Simard, J. F., Gabay, C., \& Guerne, P.-A. (2012). for the SCQM physicians. Evidence for differential acquired drug resistance to anti-tumour necrosis factor agents in rheumatoid arthritis. Rheumatology (Oxford), 51(5), 22-30.

[15] Michaud, K., Messer, J., Choi, H. K., \& Wolfe, F. (2003). Direct medical costs and their predictors in patients with rheumatoid arthritis: a three-year study of 7,527 patients. Arthritis Rheum, 48, 2750-62.

[16] Dixon, W. G., Hyrich, K. L., Watson, K. D., Lunt, M., Galloway, J., \& Ustianowski, A. (2010). BSRBR Control Centre Consortium, Symmons DP; BSR Biologics Register. Drug-specific risk of tuberculosis in patients with rheumatoid arthritis treated with anti-TNF therapy: results from the British Society for Rheumatology Biologics Register (BSRBR). Ann Rheum Dis, 69, 522-8.

[17] Furst, D. E. (2010). The risk of infections with biologic therapies for rheumatoid arthritis. Semin Arthritis Rheum, 39, 327-46. 
[18] Singh, J. A., Furst, D. E., Bharat, A., Curtis, J. R., Kavanaugh, A. F., Kremer, J. M., Moreland, L. W., O’Dell, J., Winthrop, K. L., Beukelman, T., Bridges, S. L., Jr Chatham, W. W., Paulus, H. E., Suarez-Almazor, M., Bombardier, C., Dougados, M., Khanna, D., King, C. M., Leong, A. L., Matteson, E. L., Schousboe, J. T., Moynihan, E., Kolba, K. S., Jain, A., Volkmann, E. R., Agrawal, H., Bae, S., Mudano, AS, Patkar, N. M., \& Saag, K. G. (2012). update of the 2008 American College of Rheumatology recommendations for the use of disease-modifying antirheumatic drugs and biologic agents in the treatment of rheumatoid arthritis. Arthritis Care Res (Hoboken), 64, 625-39.

[19] Montesinos, M. C., Desai, A., \& Cronstein, B. N. (2006). Suppression of inflammation by low-dose methotrexate is mediated by adenosine A2A receptor but not A3 receptor activation in thioglycollate-induced peritonitis. Arthritis Res Ther, 8, R53.

[20] Sharp, J. T., Strand, V., Leung, H., Hurley, F., \& Loew-Friedrich, I. Treatment with leflunomide slows radiographic progression of rheumatoid arthritis: results from three randomized controlled trials of leflunomide in patients with active rheumatoid arthritis. Leflunomide Rheumatoid Arthritis Investigators Group, 43, 495-505.

[21] Kerstens, P. J., Boerbooms, A. M., Jeurissen de Graaf, ME R., Mulder, J., \& van de Putte, L. B. (2000). Radiological and clinical results of longterm treatment of rheumatoid arthritis with methotrexate and azathioprine. J Rheumatol, 27, 1148-55.

[22] Kremer, J. M., Alarcón, G. S., Lightfoot, R. W., Jr Willkens, R. F., Furst, D. E., Williams, H. J., Dent, P. B., \& Weinblatt, M. E. Methotrexate for rheumatoid arthritis. Suggested guidelines for monitoring liver toxicity. American College of Rheumatology, $37,316-28$.

[23] Morgan, S. L., Baggott, J. E., Vaughn, W. H., Austin, J. S., Veitch, T. A., Lee, J. Y., Koopman, W. J., Krumdieck, C. L., \& Alarcón, G. S. (1994). Supplementation with folic acid during methotrexate therapy for rheumatoid arthritis. A double-blind, placebo-controlled trial. Ann Intern Med, 121, 833-41.

[24] Morgan, S. L., Baggott, J. E., Vaughn, W. H., Young, P. K., Austin, J. V., Krumdieck, C. L., \& Alarcón, G. S. (1990). The effect of folic acid supplementation on the toxicity of low-dose methotrexate in patients with rheumatoid arthritis. Arthritis Rheum, 33, 9-18.

[25] Shiroky, J. B., Neville, C., Esdaile, J. M., Choquette, D., Zummer, M., Hazeltine, M., Bykerk, V., Kanji, M., St-Pierre, A., Robidoux, L., et al. (1993). Low-dose methotrexate with leucovorin (folinic acid) in the management of rheumatoid arthritis. Results of a multicenter randomized, double-blind, placebo-controlled trial. Arthritis Rheum, 36, 795-803.

[26] Alarcón, G. S., Kremer, J. M., Macaluso, M., Weinblatt, ME, Cannon, G. W., Palmer, W. R., St Clair, E. W., Sundy, J. S., Alexander, R. W., Smith, G. J., \& Axiotis, CA. (1997). Risk factors for methotrexate-induced lung injury in patients with rheumatoid 
arthritis. A multicenter, case-control study. Methotrexate-Lung Study Group. Ann Intern Med, 127, 356-64.

[27] Matsuno, H., Yoshida, K., Ochiai, A., \& Okamoto, M. (2007). Requirement of methotrexate in combination with anti-tumor necrosis factor-alpha therapy for adequate suppression of osteoclastogenesis in rheumatoid arthritis. Rheumatol, 34, 2326-33.

[28] Morabito, L., Montesinos, M. C., Schreibman, D. M., Balter, L., Thompson, L. F., Resta, R., Carlin, G., Huie, MA, \& Cronstein, B. N. (1998). Methotrexate and sulfasalazine promote adenosine release by a mechanism that requires ecto- 5 '-nucleotidasemediated conversion of adenine nucleotides. J Clin Invest, 101, 295-300.

[29] Hirohata, S., Ohshima, N., Yanagida, T., \& Aramaki, K. (2002). Regulation of human $\mathrm{B}$ cell function by sulfasalazine and its metabolites. Int Immunopharmacol, 2, 631-40.

[30] Chambers, C. D., Johnson, D. L., Robinson, L. K., Braddock, S. R., Xu, R., Lopez-Jimenez, J., Mirrasoul, N., Salas, E., Luo, Y. J., Jin, S., \& Jones, K. L. (2010). Organization of Teratology Information Specialists Collaborative Research Group. Birth outcomes in women who have taken leflunomide during pregnancy. Arthritis Rheum, 62, 1494-503.

[31] Brent, R. L. Teratogen update: reproductive risks of leflunomide (Arava); a pyrimidine synthesis inhibitor: counseling women taking leflunomide before or during pregnancy and men taking leflunomide who are contemplating fathering a child. Teratology, 63(2), 106-12.

[32] Ben-Zvi, I., Kivity, S., Langevitz, P., \& Shoenfeld, Y. (2012). Hydroxychloroquine: from malaria to autoimmunity. Clin Rev Allergy Immunol, 42, 145-53.

[33] Fox, R. I., \& Kang, H. I. (1993). Mechanism of action of antimalarial drugs: inhibition of antigen processing and presentation. Lupus, 2(1), S9-12.

[34] Kyburz, D., Brentano, F., \& Gay, S. (2006). Mode of action of hydroxychloroquine in RA-evidence of an inhibitory effect on toll-like receptor signaling. Nat Clin Pract Rheumatol, 2, 458-9.

[35] Tsakonas, E., Fitzgerald, A. A., Fitzcharles, M. A., Cividino, A., Thorne, J. C., M'Seffar, A., Joseph, L., Bombardier, C., \& Esdaile, J. M. (2000). Consequences of delayed therapy with second-line agents in rheumatoid arthritis: a 3 year followup on the hydroxychloroquine in early rheumatoid arthritis (HERA) study. J Rheumatol, 27, 623-9.

[36] O’Dell, J. R., Blakely, K. W., Mallek, J. A., Eckhoff, P. J., Leff, R. D., Wees, S. J., Sems, K. M., Fernandez, A. M., Palmer, W. R., Klassen, L. W., Paulsen, G. A., Haire, C. E., \& Moore, G. F. (2001). Treatment of early seropositive rheumatoid arthritis: a two-year, double-blind comparison of minocycline and hydroxychloroquine. Arthritis Rheum, $44,235-41$.

[37] O’Dell, J. R., Paulsen, G., Haire, CE, Blakely, K., Palmer, W., Wees, S., Eckhoff, P. J., Klassen, L. W., Churchill, M., Doud, D., Weaver, A., \& Moore, G. F. (1999). Treatment 
of early seropositive rheumatoid arthritis with minocycline: four-year followup of a double-blind, placebo-controlled trial. Arthritis Rheum, 42, 1691-5.

[38] Tilley, B. C., Alarcón, G. S., Heyse, S. P., Trentham, D. E., Neuner, R., Kaplan, D. A., Clegg, DO, Leisen, J. C., Buckley, L., Cooper, S. M., Duncan, H., Pillemer, S. R., Tuttleman, M., \& Fowler, S. E. Minocycline in rheumatoid arthritis A 48-week, doubleblind, placebo-controlled trial. MIRA Trial Group, 122, 81-9.

[39] Kloppenburg, M., Breedveld, F. C., Terwiel, J. P., Mallee, C., \& Dijkmans, BA. (1994). Minocycline in active rheumatoid arthritis. A double-blind, placebo-controlled trial. Arthritis Rheum, 37, 629-36.

[40] Federici, T. J. (2011). The non-antibiotic properties of tetracyclines: clinical potential in ophthalmic disease. Pharmacol Res, 64, 614-23.

[41] Mimori, T. (2004). Anti-rheumatic drugs. In: Ochi T, Yamamoto K, Ryuu. J, editors. Manual of diagnosis and guideline for treatment of RA. Tokyo: Japanese rheumatism foundation, 84-98, in Japanese.

[42] Ichikawa, Y., Saito, T., Yamanaka, H., Akizuki, M., Kondo, H., Kobayashi, S., et al. (2005). Therapeutic effects of the combination of methotrexate and bucillamine in early rheumatoid arthritis: a multicenter, double-blind, randomized controlled study. Mod Rheumatol, 15, 323-8.

[43] Matsuno, H., Sugiyama, E., Muraguchi, A., Nezuka, T., Kubo, T., Matsuura, K., \& Tsuji, H. (1998). Pharmacological effects of SA96 (bucillamine) and its metabolites as immunomodulating drugs--the disulfide structure of SA-96 metabolites plays a critical role in the pharmacological action of the drug. Int J Immunopharmacol, 20, 295-304.

[44] Hirohata, S., \& Lipsky, P. E. (1994). Comparative inhibitory effects of bucillamine and D-penicillamine on the function of human B cells and T cells. Arthritis Rheum, 37, 942-50.

[45] Hirohata, S., \& Lipsky, P. E. (1993). Regulation of B cell function by bucillamine, a novel disease-modifying antirheumatic drug. Clin Immunol Immunopathol, 66, 43-51.

[46] Suematsu, A., Tajiri, Y., Nakashima, T., Taka, J., Ochi, S., Oda, H., Nakamura, K., Tanaka, S., \& Takayanagi, H. (2007). Scientific basis for the efficacy of combined use of antirheumatic drugs against bone destruction in rheumatoid arthritis. Mod Rheumatol, 17(1), 17-23.

[47] Tsuji, F., Seki, I., Aono, H., Odani, N., Mizutani, K., Okamoto, M., \& Sasano, M. (2007). Bucillamine mechanism inhibiting IL-1beta-induced VEGF production from fibroblast-like synoviocytes. Int Immunopharmacol, 7, 1569-76.

[48] Tsuji, F., Setoguchi, C., Okamoto, M., Seki, I., Sasano, M., \& Aono, H. (2012). Bucillamine inhibits CD40-mediated Akt activation and antibody production in mouse Bcell lymphoma. Int Immunopharmacol, 14, 47-53.

[49] Kawai, S., Takeuchi, T., Yamamoto, K., Tanaka, Y., \& Miyasaka, N. (2011). Efficacy and safety of additional use of tacrolimus in patients with early rheumatoid arthritis 
with inadequate response to DMARDs--a multicenter, double-blind, parallel-group trial. Mod Rheumatol, 21, 458-68.

[50] Kirwan, J. R. (1999). Conceptual issues in scoring radiographic progression in rheumatoid arthritis. J Rheumatol, 26, 720-5.

[51] Matsuno, H. (2010). Medical economy. In:Abe C, Kondo M, Matsubara T, Yasaki K. The manual of rheumatoid arthritis therapy with biologics. Tokyo:NIHON IGAKUKAN, 200-209.

[52] van der Bijl, A.E., et al. (2007). Infliximab and methotrexate as induction therapy in patients with early rheumatoid arthritis. Arthritis Rheum, 56(7), 2129-34.

[53] van den Broek, M., Dirven, L., Klarenbeek, N. B., Molenaar, T. H., Han, K. H., Kerstens, P. J., Huizinga, T. W., Dijkmans, BA, \& Allaart, C. F. (2012). The association of treatment response and joint damage with ACPA-status in recent-onset RA: a subanalysis of the 8-year follow-up of the BeSt study. Ann Rheum Dis, 71(2), 245-8.

[54] Chiu, Y., Ostor, A. J., Hammond, A., Sokoll, K., Anderson, M., Buch, M., Ehrenstein, M. R., Gordon, P., Steer, S., \& Bruce, I. N. (2012). Access to the next wave of biologic therapies (Abatacept and Tocilizumab) for the treatment of rheumatoid arthritis in England and Wales : Addressing treatment outside the current NICE guidance. Clin Rheumatol, 10.1007/s10067-011-1936-6.

[55] Moreland, L. W., O’Dell, J. R., Paulus, H. E., Curtis, J. R., Bathon, J. M., William, St., Clair, E., Louis, Bridges. S., Jr Zhang, J., Mc Vie, T., Howard, G., van der Heijde, D., \& Cofield, S. S. for the TEAR Investigators. A randomized comparative effectiveness study of oral triple therapy versus etanercept plus methotrexate in early, aggressive rheumatoid arthritis. Arthritis Rheum, 10.1002/art.34498.

[56] van Vollenhoven, R. F., Geborek, P., Forslind, K., Albertsson, K., Ernestam, S., Petersson, I. F., Chatzidionysiou, K., \& Bratt, J. Swefot study group. Conventional combination treatment versus biological treatment in methotrexate-refractory early rheumatoid arthritis: 2 year follow-up of the randomised, non-blinded, parallelgroup Swefot trial. Lancet, 379(9827), 1712-20.

[57] Matsuno, H. (2011). Directions in pharmacotherapy desired by patients with rheumatoid arthritis-When to use traditional disease modifying antirheumatic drugs versus biological agents-. Clin Rheumatol, 23(4), 356-364.

[58] Hetland, M. L., Christensen, I. J., Tarp, U., Dreyer, L., Hansen, A., Hansen, I. T., Kollerup, G., Linde, L., Lindegaard, H. M., Poulsen, U. E., Schlemmer, A., Jensen, D. V., Jensen, S., Hostenkamp, G., \& Ostergaard, M. (2010). All Departments of Rheumatology in Denmark. Direct comparison of treatment responses, remission rates, and drug adherence in patients with rheumatoid arthritis treated with adalimumab, etanercept, or infliximab: results from eight years of surveillance of clinical practice in the nationwide Danish DANBIO registry. Arthritis Rheum, 62(1), 22-32. 
